\title{
Framework for the Application of System Techniques (FAST) as Services Supporting Evaluation in Primary Clinic Semarang Health Polytechnic
}

\author{
Irmawati, Edy Susanto, Adhani Windari \\ Poltekkes Kemenkes Semarang, Indonesia, Poltekkes Kemenkes Semarang, Indonesia, Poltekkes \\ Kemenkes Semarang, Indonesia
}

\begin{abstract}
Medical record service information system aims to provide information to facilitate management in the service to patients and facilitate leadership in evaluating services. Therefore, it needs good medical record data management. However, the current medical record management in Primary Clinic Poltekkes Kemenkes Semarang was found to be problems, both from the Input, process, and output, so that information needs for the leader to evaluate health service become obstructed. The purpose of this research is to produce medical record information system as supporting service evaluation in Primary Clinic Poltekkes Semarang.
\end{abstract}

System development is based on FAST steps (Framework for the Application of System Techniques). The research design used pre-experimental one group pre and post test. The research variables are completeness, accuracy, accessibility, conformity, and clarity of information. The method of data processing using descriptive analysis using weighted mean and Sign Test.

Descriptive analysis results show the weighted average value of information quality after system development is greater than before system development. Sign Test test results indicate the difference in the quality of information before and after system development. Conclusion information system developed is better than old information system. Required supports recommended are in supporting facilities and infrastructure to implement new information system as well as maintenance and evaluation of system reliability after implemented.

Keywords: Service Information System, FAST, completeness, accuracy, accessibility, conformity, and clarity

\section{INTRODUCTION}

Primary clinic managed by Health Polytechnic in Semarang, Indonesia is one of the supporters of the government program in meeting the needs of the community for health service facilities consisting of general, dental, maternal and child health polyclinics. The clinic is obliged to provide safe and quality health services to give priority to the best interests of the patient. To improve the quality of service evaluation at each level of management is conducted. Evaluation activities at Clinic Pratama are done by analyzing the report on the number of patient visits, actions and financial reports based on the recapitulation of the number of medical actions each month. The lack of reports presented impedes the management to evaluate service and decision making in the development of service quality in the clinic.

Preliminary study on the clinical record, encountered the problem that the patient's social data item on the new patient registration form is incomplete; social and medical data were recorded in different books, investigation has not been documented, and the report is not complete (only the number of patients, action and medical expenses). Therefore, it is necessary to develop an electronic informationbased medical information system that is expected to be able to present information to evaluate service in the respective polyclinic.

\section{Literature REVIEW}

Medical information systems, in general, are different in some functions, depending on what type of clinic they are created for. However, a great number of functions are the same and they are building the unique base. The concept of medical records in both paper and electronic formats is a means of documenting the main data/information in health care centers. The main purpose of the medical record, Hatta (2011): a. as the main evidence that justifies the existence of the patient, b. documenting 
services provided to patients, c. management of service, d. support service, e.financing. The system is made up of interrelated and influencing elements in terms of Input, Process, and Output with the characteristics of quality information: accessibility, complete, flexible, relevant, accurate, timely, and clear.

Bentley and Whitten (2007) define system analysis as a problem-solving technique that decomposes a system into its component pieces for the purpose of studying how well those component parts work and interact to accomplish their purpose. It is a prerequisite to systems design, the specification of a new and improved system. Systems analysis definitions stated before were shifting from classical to a more contemporary definition. Systems analysis is a term that collectively describes the analysis phases in the context of the full classic route for the Framework for the Application of Systems Thinking (FAST) methodology which consists of eight steps. Those steps are: a preliminary study, problem identification, needs analysis, decision analysis, system design, system development, system implementation and system maintenance.

Definition of Health Information System is "integrated effort to collect, process, report and use health information and knowledge to influence policy-making, program action, and research"

This definition means that data must be processed into information to be used for the preparation of activities or programs and research. The medical record is a file containing notes, and documents about patient's identity, examination, treatment, actions and other services to the patient on health service facilities (Permenkes, 2008). The function or purpose of the medical record is to support achievement the orderly administration in the framework of efforts improvement of health services. Without being supported by a good and right record of a medical management system, then the orderly administration will not work.

\section{Methodology}

This study applies descriptive research evaluation approach to assess the quality of information produced before and after the development of information systems where research design used pre experimental (one group pre and post test). The independent variables are 1) FAST Method (Framework for the Application of System Technique) 2) Quality of information with indicators completeness, accessibility, conformity of information, accuracy of information, clarity of information and service evaluation while dependent variable is implementation of medical information system with the indicators of 1) management of medical records, 2) data admissions and services provided to patients, 3) database 4) process of medical record information system to produce output and 5) reports used to support service evaluation.

Qualitative study for the purpose of confirmation was performed through observation and depth interview to key informants as well as conducting a focus group discussion with the director, person in charge, coordinator, registration officer and service provider implementing medical records information system as a supporting service evaluation in Polyclinic managed by Polytechnic of Health Ministry in Semarang.

Under the FAST Method, the steps in limited until implementation only as maintenance does not belong to system evaluation. The steps are defined as follows:

Preliminary investigation: knowing the problems and opportunities of the current system and the direction of management as well as to find out the scope and feasibility of developing the information system.

Problem analysis: analyzing the current medical record information system, analyzing problems in the preliminary study and looking for a solution, identifying hardware, software and users (brain ware) for the implementation of information systems to be developed.

Requirement Analysis aims at considering technical feasibility, operations, schedule, economy and law based on the interview results. Identification of medical record information system requirement in the respective clinic indicates the following:

Input requirements: patient identity data, patient examination result data, action data, cost data treatment.

Process: Management is done by processing the existing data sources into information in the form of reports. For external reports to the City Health Office, it is done by recapitulating the records in the register book, calculated manually, then transferred in the monthly report form. As for internal reports, reports are presented using a computer. 
Output requirements: Reports/trends of patient visits, disease reports, clinical reports, preterm clinical reports, investigation reports, inspection cost reports, patient data, examination data, inspection data, cost data.

Decision analysis aims at identifying feasibility and determining the alternative choice of system by considering the economic aspect, resources, and facilities available.

Design System: database design, output design, input design and interface design.

Building a new system (Construction): translating the design results into computer programming using PHP programming language and database using MySQL.

System Implementation Stage: a pilot project and explanation of the new system in terms of operational as well as information that can be generated.

\section{RESUlt AND DisCuSSION}

The service activities carried out in Primary Clinic in Health Polytechnic Semarang begins with patient registration activities for both new patients and old patients, then the patient will go to the service to get the health service. Laboratory examination, nutrition consultation, and other investigation are done specially for elderly assisted by Community Service Unit. After the examination, the patient pays the service charge at the cashier.

By applying the framework of FAST, the current conditions are highlighted.

The preliminary investigation aims at knowing the problems and opportunities of the current system and the direction of management as well as to find out the scope and feasibility of developing the information system. Implementation of service evaluation activities involves administrative officers responsible and person in charge in the clinic. The medical record information system when the research conducted is in accordance with the procedures to conduct service evaluation, but the reports resulted have not been able to meet the needs of leaders, in terms of completeness of information, accuracy of information, ease of information access, conformity and clarity in presenting the information making evaluation became obstructed.

Problem analysis aims at analyzing the current medical record information system, analyzing problems in the preliminary study and looking for a solution, identifying hardware, software and users (brain ware) for the implementation of information systems to be developed. Problems on medical record information system when research is conducted are:

- Completeness: incomplete patient's social data, incomplete service activity reporting.

- Accessibility: Data storage has not used the database where access is still manual.

- Conformity: The resulting report / information does not meet the leader's need for service evaluation.

- Accuracy: Recapitulation of the top ten illnesses is not accurate due to manual and incomplete recording.

- Clarity: The flow of medical record management is not clear.

These problems of medical record information system can be solved by the use of information technology.

Requirement Analysis aims at considering technical feasibility, operations, schedule, economy and law based on the interview results.

Decision analysis: the process of identifying feasibility and determining the alternative choice of system by considering the economic aspect, resources, and facilities available. New system development model will be Microsoft Windows (MS) operating system, PHP Script Language Tool 5.6.2. PHP Framework (Laravel 5.3), database server MySQL and Database version 5.0.51. The differences between the current system and the system to be developed is that registration data will contain additional patient identity data and service part data; data of service providers and units are additional in the form of physician data, examination type data, examination result data and investigation data; Data of goods / drugs in the form of group data of goods / drugs, classes of goods / drugs, pharmacology groups, producer data, data of dosage forms and data of goods / drugs; Information systems. The medical record section includes patient examination reports and monthly reports. 
Design System is focused on database design, output design, input design and interface design. Based on observation and interview with the user then obtained the output needs with the format: table/graph, medical: paper, tools: printer, period: annual with the outputs of : reports of old/new patient visit, inspection report, medication use, supplementary investigation report, clinical activity report. The results of the input design on the clinical medical record information system include the design of inputs in the administration section with form: tool, tool: keyboard and input name: patient identity data, physician data, examination data, disease data, drug data, action data, and cost data.

Building a new system (Construction) aims at translating the design results into computer programming using PHP programming language and database using MySQL. Programming means converting the logic design results into encoding operations using programming language. The programmer then validates the system by testing program modules.

System Implementation Stage: this is a pilot project and explanation of the new system in terms of operational as well as information that can be generated. Medical record information system as supporting service evaluation is applied at the clinic of Health Polytechnic in Semarang. Socializing the new system is then conducted to introduce a new system to the relevant officers then system trial is performed in terms of 1) trial of simplicity in structure and operation/easy of use, 2) testing completeness, 3) testing the ease of accessing information and 4) testing the accuracy and clarity of information to conduct service evaluation.

System information quality evaluation is done by calculating the average weight before and after system development using the Likert scale. From the result of information quality evaluation, it is found that the development of nurse registration information system to support nurse supervision has been able to overcome the problem of quality of information in the form of completeness, accessibility, timeliness, clarity, and relevance. This can be seen from the overall average weight score before the development of systems $=1.07$ and after the development of the system $=2.00$ with a margin of 0.98. Thus, it can be concluded that there is an increase in the quality of information generated by the development of the system.

The difference test between the old and new system is calculated for each observation with the Wilcoxon signed-rank test - a non-parametric statistical hypothesis test used when comparing two related samples, matched samples, or repeated measurements on a single sample to assess whether their population means ranks differ and the data used is the weighted average. From the calculation with the aids of SPSS for Windows, it is found there is a significant difference between the quality of information generated by the old system with the quality of information generated by the new system. In the new system, the resulting information is complete and relevant to user needs, meaning the new system produces useful information to support service evaluation, more timely, information available when needed by the user, more accessible, able to present information in the form of tables and graphs that make it easier for leaders to analyse.

\section{Conclusion}

Medical record information system as supporting of service evaluation in the respective is clinic not yet maximal as some problems are found like in complete patient recording, patient data collection done by registering at register book, manual data processing and report not yet complete. The results of testing on the proposed information system indicate capability to overcome the problems. The resulting report can be used to evaluate the service at clinic of Health Polytechnic in Semarang. If implemented, the quality of information medical records information system as a support service evaluation is much better and complete than the old information system. However, for the implementation of the system information needs to be done maintenance and evaluation of system reliability and additional supporting facilities that such as storage document cabinets for patient medical records. Furthermore, to ensure efficiency, the medical record information system needs to be developed into a multi-user.

\section{REFERENCES}

[1] Hatta. (2011). "Pedoman Manajemen Informasi Kesehatan di Sarana Pelayanan Kesehatan," Jakarta: UI Press.

[2] Peraturan Menteri Kesehatan RI nomor 269/MENKES/PER/III/2008 Tentang Rekam Medis.

[3] Whitten, J. L. (2007). Bentley. LD, “Systems Analysis \& Design Methods, ”. Mc.Graw Hill. 